\title{
Asthma symptoms: influence of personality versus clinical status
}

\author{
C. Put*, M. Demedts*, O. Van Den Bergh ${ }^{+}$, K. Demyttenaere**, G. Verleden*
}

\begin{abstract}
Asthma symptoms: influence of personality versus clinical status. C. Put, M. Demedts, O. Van Den Bergh, K. Demyttenaere, G. Verleden. C) ERS Journals Ltd 1999.

ABSTRACT: The hypothesis that symptom-reporting in asthmatics does not necessarily correspond with clinical status, but is related to negative affectivity was investigated.

One hundred and sixteen asthmatic patients filled out the Asthma Symptom Checklist (ASC), the Negative Emotionality Scale (NEM), and the McMaster-Asthma Quality-of-Life Questionnaire (AQLQ). The patients were grouped as either hospitalized, outpatient previously hospitalized or outpatient not previously hospitalized for asthma. Lung function data and Asthma Severity Scores (ASS) were also collected. The hospitalized group was retested after 3 months.

The hospitalized group had lower AQLQ scores, higher ASS scores and worse lung function than both outpatient groups. However, the hospitalized group and the outpatients previously hospitalized group had higher ASC scores and NEM scores than the outpatients not previously hospitalized group. After discharge, when the hospitalized group had become clinically stable, their ASC and NEM scores remained comparable to those of the outpatient previously hospitalized group.

Symptom-reporting in asthmatics is not necessarily in accordance with clinical status, but may be directly or indirectly mediated by personality, such as negative affectivity.
\end{abstract}

Eur Respir J 1999; 13: 751-756.

Asthma symptoms are of great importance for both the physician and the patient. Medical decisions are based upon the presence of asthma complaints, in addition to objective information about the patient's condition. The patient's perception of symptoms determines other aspects of illness behaviour, such as remedial action, and utilization of the health care system [1]. In some [2], but not all studies [3], the correlation between asthma symptoms and objective respiratory parameters, such as lung function, appears weak or even nonexistent. NGUYEN et al. [4] found that $20 \%$ of patients with asthma underestimated the disease severity, whereas $27 \%$ overestimated the severity of their disease. Consequently, investigation of the processes that influence symptom perception and its clinical implications is necessary.

A number of studies have established a relationship between emotional status and asthma symptoms $[5,6]$. Asthmatics who are emotionally distressed report more symptoms than others. However, the causality of this relationship remains unclear. Studies on the presence of personality traits in asthmatics have helped to clarify certain findings regarding medical outcome. The tendency for an asthmatic to react with panic/fear during an asthma exacerbation, together with the level of airway hyperreactivity, predicts the hospitalization rate, length of hospitalization and prescription of steroids at discharge [7, 8]. The personality trait defined as "negative affectivity", or the tendency to experience negative emotions such as depression, anxiety and irritability, is important in understanding sickness behaviour and symptoms of patients with somatic
Depts of *Pulmonology, and **Psychiatry, University Hospital Gasthuisberg, Leuven, Belgium; 'Dept of Psychology, Katholieke Universiteit Leuven, Leuven, Belgium.

Correspondence: G.M. Verleden, Dept of Pulmonary Medicine, University Hospital Gasthuisberg, 49 Herestraat, B-3000 Leuven, Belgium. Fax: 3216346803

\section{Keywords: Asthma \\ hospitalization \\ negative affectivity \\ personality \\ quality of life \\ symptoms}

Received: May 61998

Accepted after revision November 291998

Supported by Astra Belgium complaints [9]. The value of this personality trait has not been explored in relation to asthma symptoms.

In the first part of this study, the relationship between symptom-reporting and the presence of negative affectivity as a personality trait in hospitalized and outpatient asthmatics was investigated. In the second part, the hypothesis that symptom-reporting in asthmatics does not necessarily correspond with changes in clinical status, but is related to negative affectivity was prospectively investigated.

\section{Material and methods}

Subjects

Outpatients and hospitalized patients were consecutively recruited from the outpatient clinic and hospital wards of the Pulmonary Division at the University Hospital Gasthuisberg, Leuven, Belgium. Hospital admission for asthma was determined by the findings during clinical examination at the Emergency Department. The time frame of the study was 9 months. The inclusion criteria were as follows: 1) diagnosis of asthma according to the criteria of the American Thoracic Society [10]; 2) aged 18$70 \mathrm{yrs}$; and 3) asthma complaints during the preceding month.

\section{Study design and procedure}

Three groups of asthmatics were compared: 1) hospitalized patients (H group); 2) outpatients with previous 
asthma-related hospitalization (OH group); and 3) outpatients without previous asthma-related hospitalization $(\mathrm{O}$ group). The $\mathrm{OH}$ group served as a "control" group, because the patients were comparable to the $\mathrm{O}$ group in terms of current disease severity and functional status, except that the patients of the $\mathrm{OH}$ group had experienced an acute asthma exacerbation in the past for which they were hospitalized. In order to prospectively confirm the relationship between negative affectivity and symptom-reporting, the $\mathrm{H}$ group was retested $\sim 3$ months after discharge, when the patients were clinically stable.

Patients gave informed consent to participate in this study. Information on lung function, medication use and frequency of asthma complaints was collected from a review of medical files and a structured interview. Patients filled out the questionnaires independently. Hospitalized patients filled out the questionnaires on day 2 or day 3 . Outpatients were seen after routine consultation with a pulmonologist. Both medical and subjective data refer to the patient's current clinical status.

Nineteen outpatients who had agreed to participate preferred to fill out the questionnaires at home owing to shortage of time. They were instructed to fill out the questionnaires independently and return them by mail the same day.

\section{Methods}

The Asthma Symptom Checklist (ASC) contains 36 items and describes the subjective symptomatology of asthma [11]. The patient indicates the frequency of a symptom experienced during an asthma-exacerbation using a 5point scale (1 never; 5 always). A Dutch translation was reviewed by three pulmonologists, resulting in a few adjustments concerning the description of respiratory symptoms. Seven patients with asthma filled out the first version of the translated questionnaire. Every item was subsequently discussed separately with each patient to establish complete comprehension of the meaning. A few final adjustments were then made. Reliability testing was based upon the data of all outpatients $(\mathrm{O}, \mathrm{OH}$ and followup $\mathrm{H}$ group; $\mathrm{n}=114$ ). Confirmatory factor analysis and oblique transformation of the items of ASC resulted in six subscales, similar to that described previously [12]: fatigue (6 items), symptoms of bronchoconstriction (5 items), shortness of breath (3 items), anxiety ( 8 items), irritation (6 items) and symptoms of hyperventilation (6 items). The items "coughing" and "mucous congestion" had high loadings on, and were the only significant loadings of, two additional factors. For reasons concerning validity and reliability of the subscales, these items were left out during further data analyses. Internal consistency of five of the six subscales was high (Cronbach's alpha: 0.93, 0.88, 0.86, $0.87,0.92)$. The loading for the subscale "hyperventilation symptoms" was lower, but still acceptable (0.76). Retesting of the patients when they were clinically stable revealed high reliability (Spearman's rank for all subscales: 0.71 , $0.76,0.86,0.81,0.82,0.61)$.

The Negative Emotionality Scale (NEM) consists of 14 items, and is part of the Multidimensional Personality Questionnaire [13]. The scale measures "negative affectivity" as a personality trait, including a variety of negative emotional conditions such as irritability, nervousness, and emotional instability.
The Asthma Quality-of-Life Questionnaire (AQLQ) [14] measures health-related limitations in quality of life experienced by adult asthmatics during the previous 2 weeks. Thirty-two items fall into four domains: symptoms (12 items), emotions (5 items), exposure to environmental stimuli (4 items) and activity limitations (11 items). The individual scores range from 1 (low quality of life) to 7 (high quality of life). All the subscales, except for "exposure to environmental stimuli" had high internal consistency (Cronbach's alpha: 0.92, 0.82, 0.70, 0.89 respectively). Retesting after $\sim 12$ weeks, when the patients were clinically stable, revealed a high retest reliability (from 0.55 to 0.59 ).

Asthma severity was assessed by means of a structured interview questionnaire. The Asthma Symptoms Score (ASS) refers to symptomatology over the previous 14 days (symptoms of bronchial reactivity to nonspecific stimuli, hyperventilation asthma, exercise-induced asthma, nocturnal asthma, frequency of morning dip symptoms, frequency of inhaled symptomatic treatment) [15]. The score ranges between 0 and 22 .

\section{Data analysis}

The Chi-squared test was used to analyse the significance of two- or three-dimensional tables for the comparison of sex and medication use between the three asthma groups. Nonparametric analyses were employed for comparisons of the ordinal measures, specifically ASC, NEM, and AQLQ between the three separate patient groups [16]. The Kruskall-Wallis test established the presence of group differences, the magnitude of which was determined by a Mann-Whitney U-test. A parametric analysis of variance was used to compare the patient groups with respect to lung function data, age and duration of illness. Comparisons with $\mathrm{p}<0.01$ were considered as significant. Relationships were estimated by means of the Spearman's rank correlation coefficient. All statistical analyses were performed with Statview 4.5 for Macintosh (Abacus Concepts, Berkeley, CA, USA).

\section{Results}

\section{Patients}

Demographics. One hundred and twenty-six patients were asked to take part in the study. Five were excluded for illiteracy (1 patient), no reading glasses available (1 patient), and problems with filling out the questionnaires (3 patients). Another five patients refused to participate. The analyses were, therefore, based upon the data of 116 patients: 56 males and 60 females, with a mean age of $43 \pm 16$ yrs (table 1 ).

All patients who had filled out the questionnaires at home returned them on the same day and reported compliance to the instruction of filling out the questionnaire on their own. These patients did not differ in any of the clinical parameters from the other patients in the study. Two cases in the H group were lost to follow-up owing to relocation.

Clinical characteristics. Thirty-three patients were hospipitalized for an acute asthma exacerbation. Average duration of hospitalization was 12 days. Eighty-three subjects 
Table 1. - Demographic and clinical characteristics of the asthmatic patients either hospitalized (H group) outpatients previously hospitalized (OH group) or outpatient not previously hospitalized (O group)

\begin{tabular}{|c|c|c|c|c|}
\hline & $\underset{\substack{\mathrm{H} \\
\mathrm{group}}}{\mathrm{n}=33)}$ & $\begin{array}{l}\mathrm{OH} \\
\text { group } \\
(\mathrm{n}=45)\end{array}$ & $\underset{(\mathrm{n}=38)}{\mathrm{O}}$ & $\begin{array}{c}\text { H group } \\
\text { follow-up } \\
(n=31)\end{array}$ \\
\hline Age yrs $^{+}$ & $45 \pm 17$ & $40 \pm 16$ & $42 \pm 17$ & $44 \pm 16$ \\
\hline Sex M/F & $14 / 19$ & $21 / 24$ & $20 / 18$ & $14 / 17$ \\
\hline Asthma duration yrs ${ }^{+}$ & $15 \pm 12$ & $12 \pm 11$ & $13 \pm 13$ & $14 \pm 11$ \\
\hline ASS & $16 \pm 6$ & $9 \pm 5$ & $8 \pm 4$ & $6 \pm 4$ \\
\hline \multicolumn{5}{|l|}{$\begin{array}{l}\text { Lung function } \\
\% \text { pred }^{+}\end{array}$} \\
\hline $\begin{array}{c}\text { FEV1 admission } \\
\text { discharge }\end{array}$ & $\begin{array}{l}67 \pm 22 * * \\
82 \pm 19\end{array}$ & $82 \pm 19$ & $85 \pm 23$ & $91 \pm 24$ \\
\hline $\begin{array}{c}\text { FVC admission } \\
\text { discharge }\end{array}$ & $\begin{array}{l}90 \pm 17 * * \\
102 \pm 15\end{array}$ & $105 \pm 14$ & $102 \pm 15$ & $106 \pm 15$ \\
\hline \multicolumn{5}{|l|}{ Medication \% } \\
\hline $\begin{array}{l}\text { Inhaled } \\
\beta_{2} \text {-adrenergics }\end{array}$ & 100 & 92 & 90 & 94 \\
\hline SA & 71 & 41 & 65 & 63 \\
\hline LA & 4 & 10 & 8 & 7 \\
\hline $\mathrm{SA}+\mathrm{LA}$ & 25 & 41 & 17 & 24 \\
\hline Inhaled steroids & 100 & 93 & 85 & 94 \\
\hline Theophyllines & 43 & 33 & 32 & 35 \\
\hline Anticholinergics & 57 & 47 & 20 & 40 \\
\hline p.o. or i.v. steroids & 97 & 15 & 3 & 8 \\
\hline
\end{tabular}

M: male; F: female; ASS: Asthma Symptom Score; FEV1: forced expiratory volume in one second; FVC: forced vital capacity; SA: short-acting; LA: long-acting. ${ }^{+}$: results are mean \pm SD from the number of patients included in each group. ${ }^{* *}: \mathrm{p}<0.01$, compared to the outpatient groups.

were outpatients, 45 of whom had been hospitalized at least once during the previous 10 yrs for exacerbation of asthma symptoms (hospitalization rate: mean 3 , range 2-15; time since last hospitalization: $13 \pm 17$ months (mean $\pm \mathrm{sD})$, range 2-96 months). The three groups $(\mathrm{H}$, $\mathrm{OH}$, and $\mathrm{O}$ ) did not differ with regard to age and duration of illness. Although more females were hospitalized, there was no sex difference between the three groups (Chi-Squared=1.34; NS). At the beginning of their hospitalization, subjects had a lower average forced vital capacity (FVC) and forced expiratory volume in one second (FEV1) values than outpatient subjects. These differences were not evident at discharge. During hospitalization, lung function data were collected twice: during the first 3 days of hospitalization (average 2 days) and 1 or 2 days before discharge. Consequently, the mean lung function values "at admission" referred to the patient's condition after they had received medical attention at Emergency Services. An FEV1 at admission is not routinely performed in the authors' institution.

Seven patients (one currently hospitalized, six previously hospitalized) needed mechanical ventilation at one point in the past. Respiratory function of these patients tended to be worse, but the difference did not reach statistical significance (FEV1 $65 \pm 12 \%$ versus $82 \pm 22 \%$; FVC $94 \pm 20 \%$ versus $102 \pm 15 \%$ ).

Twenty-two inpatients received oral steroids, and 10 inpatients were administered steroids intravenously. One hospitalized patient did not receive treatment with systemic steroids due to osteoporosis. Compared to outpatients, more hospitalized patients were taking p.o./i.v. steroids
(Chi-squared=19.7; $\mathrm{p}<0.0001$ ). Furthermore, patients of the $\mathrm{H}$ and $\mathrm{OH}$ groups took more anticholinergic medication than patients from the $\mathrm{O}$ group (Chi-squared=9.4; $\mathrm{p}<0.01)$. The $\mathrm{OH}$ group was taking proportionally more long-acting $\beta_{2}$-agonists than the $\mathrm{H}$ and $\mathrm{O}$ groups (51 versus 29 and $25 \%$, respectively; Chi-squared $=13.9$; $\mathrm{p}<0.05$ ). The three groups did not differ with regard to the intake of inhaled steroids and theophyllines. At the time of followup, the patients in the $\mathrm{H}$ group were clinically stable (ASS $6 \pm 4$; FVC $106 \pm 15 \%$; FEV1 91 $\pm 24 \%$ ). Medication use after discharge was comparable to the $\mathrm{O}$ group except for anticholinergic agents. The elevated consumption of systemic steroids in the $\mathrm{OH}$ and follow-up $\mathrm{H}$ groups was due to a recent disease exacerbation.

During the period preceding hospitalization $18 \%$ of the $\mathrm{H}$ group were taking systemic steroids, $52 \%$ inhaled steroids, $83 \% \beta_{2}$-agonists, 54\% anticholinergics and 37\% theophyllines. Half of the patients who were not taking inhaled steroids had discontinued therapy on their own initiative; in the other cases inhaled steroids were not prescribed by their general practitioner.

\section{Asthma symptoms and negative affectivity}

Compared to the $\mathrm{O}$ group, the $\mathrm{H}$ and $\mathrm{OH}$ groups had higher scores on the ASC subscales: fatigue, bronchoconstriction, dyspnoea and anxiety (table 2). On the hyperventilation subscale, the $\mathrm{H}$ group had higher scores compared to the $\mathrm{O}$ group only. The $\mathrm{H}$ and $\mathrm{OH}$ group subjects had higher NEM scores compared to the $\mathrm{O}$ group. As expected, the $\mathrm{H}$ group subjects reported a lower asthmarelated quality of life than both the outpatient groups

Table 2. - Asthma symptoms, negative affectivity and quality of life in the currently hospitalized ( $\mathrm{H}$ group), previously hospitalized ( $\mathrm{OH}$ group) and never hospitalized $(\mathrm{O}$ group) asthmatics

\begin{tabular}{lllll}
\hline & $\begin{array}{c}\mathrm{H} \\
\text { group } \\
(\mathrm{n}=33)\end{array}$ & $\begin{array}{c}\mathrm{OH} \\
\text { group } \\
(\mathrm{n}=45)\end{array}$ & $\begin{array}{c}\mathrm{O} \\
\text { group } \\
(\mathrm{n}=38)\end{array}$ & $\begin{array}{c}\text { H group } \\
\text { follow-up } \\
(\mathrm{n}=31)\end{array}$ \\
\hline $\begin{array}{l}\text { Asthma symptoms } \\
\text { (ASC) }\end{array}$ & & & & \\
Fatigue & $3.7 \pm 1.2$ & $3.2 \pm 0.9^{+}$ & $2.5 \pm 0.9^{* * *} 3.5 \pm 1.1$ \\
Symptoms of & $3.0 \pm 1.0$ & $2.9 \pm 0.9^{+}$ & $2.3 \pm 0.8^{* *}$ & $2.9 \pm 1.1$ \\
$\quad$ bronchocon stric- & & & & \\
$\quad$ tion & & & & \\
Dyspnoea & $4.1 \pm 0.73 .9 \pm 0.8^{+}$ & $3.3 \pm 0.8^{* * *} 3.7 \pm 0.9$ \\
Anxiety & $2.8 \pm 1.12 .5 \pm 1.1^{*}$ & $1.8 \pm 0.6^{* * *} 2.5 \pm 1.1$ \\
Hyperventilation & $2.1 \pm 0.91 .9 \pm 0.6^{*}$ & $1.6 \pm 0.6^{* *}$ & $2.0 \pm 1.0$ \\
Irritation & $2.8 \pm 1.2$ & $2.6 \pm 1.0$ & $2.3 \pm 0.9$ & $2.9 \pm 1.2$ \\
Negative affectivity & $7.0 \pm 4.37 .0 \pm 3.9^{+}$ & $4.5 \pm 3.7^{* *}$ & $8.0 \pm 4.2$ \\
Quality of life & & & & \\
(AQLQ) & & & & \\
Activity limitations & $3.3 \pm 1.34 .3 \pm 1.2^{* *}$ & $4.8 \pm 1.1^{* * *} 4.0 \pm 1.4$ \\
Symptoms & $3.5 \pm 1.24 .9 \pm 1.2^{* * *} 4.9 \pm 1.0^{* * * *} 4.5 \pm 1.5$ \\
Emotions & $3.8 \pm 1.64 .9 \pm 1.3^{* *}$ & $5.0 \pm 1.3^{* *}$ & $4.6 \pm 1.8$ \\
Exposure to & $4.4 \pm 1.54 .7 \pm 1.3$ & $4.9 \pm 1.3$ & $4.5 \pm 1.4$ \\
$\quad$ environmental & & & & \\
$\quad$ stimuli & & & & \\
\hline
\end{tabular}

Results are mean \pm SD from the number of patients included in each group. ASC: Asthma Symptom Checklist; AQLQ: Asthma Quality of Life Questionnaire. ${ }^{* *}: \mathrm{p}<0.01$, compared to $\mathrm{H}$ group; $* * *$ : $\mathrm{p}<0.001$, compared to $\mathrm{H}$ group; ${ }^{+}: \mathrm{p}<0.01$, compared to $O$ group; ${ }^{*}: p<0.05$, compared to $O$ group; ${ }^{*}: p<0.001$, compared to $\mathrm{O}$ group. 
on the following subscales $(p<0.01)$ : activity limitations, symptoms and emotions. Both outpatient groups had similar AQLQ scores.

Despite a lower lung function, asthmatics who had needed mechanical ventilation in the past did not differ from the others on ASC, AQLQ and NEM scores. There was no association between time since last hospitalization and ASC, AQLQ and NEM $(r<0.20)$. Correlations between total ASC scores, NEM scores and lung function (FVC) revealed different patterns in the three patient groups (table 3 ). In the $\mathrm{H}$ group, there were significant positive correlations between all three parameters; the ASC and NEM scores correlated highly in the $\mathrm{OH}$ group; in the $\mathrm{O}$ group there were no significant correlations. Quality-of-life scores in all groups were negatively related to ASS, ASC and NEM scores $(\mathrm{r}=-0.50--0.80 ; \mathrm{p}<0.05)$ and unrelated to lung function. No association was found between ASS indices and lung function and NEM scores in the groups. There was a positive correlation between ASS and ASC in the $\mathrm{H}$ and $\mathrm{O}$ groups $(\mathrm{r}=0.50 ; \mathrm{p}<0.05)$.

\section{Follow-up data}

It was possible that the patterns of asthma symptoms in the three groups could still be attributed to differences in disease severity, instead of personality (NEM). For this reason, the questionnaires were administered to the hospitalized patients after they were discharged. Despite a significant improvement in most domains of quality of life, they reported similar asthma symptoms to those during their hospitalization (table 2).

At follow-up, the significant correlations between lung function and ASC scores and NEM scores had disappeared (table 3). ASC scores had the same correlational pattern as those in the other groups. Asthma symptom scores were highly correlated to the NEM scores, as was the case in the $\mathrm{OH}$ group. Additionally, a high correlation was found between ASC scores at the time of hospitalization and at the time of follow-up $(\mathrm{r}=0.70 ; \mathrm{p}=0.002)$. The AQLQ scores were unrelated to lung function, but positively related to $\operatorname{ASC}(r=0.54 ; p<0.05)$ and NEM $(r=0.52 ; p<0.05)$.

\section{Discussion}

The purpose of the current study was to investigate symptom perception and the presence of the personality trait, "negative affectivity", in hospitalized and outpatient asthmatics.

Table 3. - Correlation between asthma symptoms, negative affectivity and lung function in asthmatic patients

\begin{tabular}{llllr}
\hline Correlations & H group & $\begin{array}{c}\text { H group } \\
\text { follow-up }\end{array}$ & $\begin{array}{c}\text { OH } \\
\text { group }\end{array}$ & O group \\
\hline Lung function ASC & $0.43^{*}$ & 0.00 & 0.03 & -0.24 \\
Lung function NEM & $0.40^{*}$ & 0.06 & 0.06 & 0.23 \\
ASC-NEM & $0.56^{* *}$ & $0.79^{* * *}$ & $0.42^{* *}$ & 0.21 \\
\hline
\end{tabular}

$\mathrm{H}$ group: hospitalized patients; $\mathrm{OH}$ group: outpatients previously hospitalized; O group: outpatients not previously hospitalized; ASC: Asthma Symptom Checklist; NEM: Negative Emotionality Scale. *: $\mathrm{p}<0.05$; **: $\mathrm{p}<0.01 ; * * *: \mathrm{p}<0.001$.
It was found that currently hospitalized and previously hospitalized outpatients did not differ with respect to the description of an asthma exacerbation. Both groups gave more severe descriptions of asthma symptoms than those described by outpatients without previous hospitalization. In addition, the $\mathrm{H}$ and $\mathrm{OH}$ groups reported more negative emotions as a disposition than the $\mathrm{O}$ group. In order to assess whether the observed patterns of symptom perception were attributable to disease-related variables such as respiratory function and medication regimen, the hospitalized patients were retested after discharge. Although clinically stable and functionally improved, their description of an asthma exacerbation as well as their level of negative affectivity were similar to their description during hospitalization.

The relationship found between asthma complaints and negative affectivity can be explained in at least four ways. Firstly, there may be a subgroup of asthmatics with lung function that is usually within normal range, but who have quite severe exacerbations with concomitantly decreased lung function. These recurrent exacerbations are accompanied by intense emotional reactions, and may lead to the development of a trait that is best described as "negative affectivity" [17]. This is not confirmed by the present data, since both outpatient groups had comparable disease severity (medication use, ASS, pulmonary function), and the subjects who had needed mechanical ventilation did not have a higher level of negative affectivity. Furthermore, the presence of an illness such as hypertension or cancer, does not necessarily lead to the development of the negative affectivity trait [18]. A second possibility is that asthmatics characterized by high negative affectivity may be more likely to develop severe respiratory changes as a result of an interaction between psychological and immunological factors. Although it has been repeatedly demonstrated that stress and negative emotions compromise cellular immunity [19], psychoimmunological studies in asthma are lacking. Accordingly, there is no evidence for this hypothesis from the present study. Thirdly, hospitalization is known to be associated with increased anxiety, especially in children, surgical patients and patients who suffered a heart attack. In the latter two cases, the psychological impact of hospitalization is related to decreased functionality [20,21]. In this study, quality of life improved after hospitalization. In addition to the lack of association between negative emotionality and time since previous hospitalization in the $\mathrm{OH}$ group, these findings do not support the hypothesis that hospitalization still has a psychological impact upon patients 3 months after discharge. Finally, asthmatic patients with a high negative affectivity personality trait may react with more symptoms to respiratory changes, in contrast to patients with low negative affectivity. This explanation is based upon the highly interoceptive orientation of individuals with high negative affectivity [22].

Irrespective of their current clinical status, patients with a disposition to experience negative emotions reported more asthma symptoms than patients not characterized by such a personality trait. The results of the current study support the notion that symptom perception is an attribution process in which symptoms are interpreted according to preconceived "disease prototypes" [23]. Symptoms that match this disease representation can be continually emphasized by the patient, even when treatment induces a 
change in the underlying pathology [24]. Similarly, it has been shown that after repeated histamine challenge testing, asthmatics become less accurate in their estimation of the degree of bronchoconstriction, while the description of asthma-related symptoms (ASC scores) remains unchanged [25]. When in a familiar situation (i.e. repeated testing), asthmatics may become less anxious and may base their symptom perception upon pre-existing cognitive schemes rather than actual respiratory changes.

Asthmatics characterized by high negative affectivity and a higher report of asthma symptoms had a greater risk of hospitalization. Hospitalization rate has previously been attributed to inadequate asthma management [26, 27]. Inferring from the medication intake of the $\mathrm{H}$ group immediately before hospital admission, the quality of asthma management might not have been optimal in this sample. While in respiratory distress, only half of the patients were taking inhaled steroids as daily treatment, $18 \%$ were taking oral steroids and $17 \%$ were not taking $\beta_{2}$-agonists. These figures were partly determined by the patient's noncompliance (i.e. $25 \%$ had discontinued intake of inhaled steroids), but also because of a lack of knowledge regarding asthma management on both the patient's part (e.g. in case of an exacerbation, a delay in consulting the general practitioner) and the part of the general practitioner.

Several studies have highlighted the predictive value of psychosocial factors for (re)hospitalization. Psychological status, i.e. depression, appears to be an important predictor of rehospitalization among patients who have been admitted with coronary artery disease [28]. Similarly, psychosocial factors, such as noncompliance, personality, social situation and lifestyle have been extensively investigated in relationship to asthma mortality and morbidity [29]. The results of this study were consistent with previous findings concerning the relationship between personality traits and medical outcome [30, 31]. Emotional instability has been related to the length of hospitalization, and dispositional anxiety is associated with rehospitalization within 6 months [30]. Similarly, patients who have attitudes marked by extremely low optimism and high panic-fear personality scale scores have been reported to have a high chance of rehospitalization [31]. One possible explanation for the link between hospitalization rate and personality traits concerns the high inspiratory and expiratory threshold values of asthmatics with high negative affectivity [32]. Anxious and dependent patients are less able to recognize added resistive loads than independent or adaptive subjects. This decreased ability to perceive respiratory changes could postpone appropriate therapy, and could therefore put this subgroup of patients at risk for hospitalization. Another explanation might lie in the patient's noncompliance to prescribed medication [33]. Both overuse of $\beta_{2}$-agonists and underuse of inhaled steroids can have detrimental effects [34]. The findings from the present study suggest that patients with high negative affectivity impress their physicians with the amount of complaints, and will be more easily hospitalized. The positive correlation between lung function and symptoms in hospitalized patients implies that the excessive complaints are not based upon a more severe clinical deterioration (table 3; $\mathrm{r}=0.43, \mathrm{p}<0.05$ ). Specifically, notwithstanding a relatively satisfactory lung function, some patients might be hospitalized because they report a great deal of hyperventilation symptoms and dyspnoea.
The value of a multidimensional method for evaluating asthma complaints is confirmed by these results. By examining different asthma symptom categories, specific subgroups of asthmatics were identified. The $\mathrm{H}$ and $\mathrm{OH}$ groups reported more symptoms of fatigue, bronchoconstriction, dyspnoea and anxiety than the $\mathrm{O}$ group. A careful evaluation of an asthmatic's subjective symptomatology, along with an objective illness assessment, is essential to reduce the patient's complaints, improve general functioning, and to discover possible biases in the patient's symptom reports [23].

The clinical implications of these findings pertain to the goals and objectives of asthma management. In this respect, appropriate asthma management necessitates a thorough understanding of the underlying processes of symptom-reporting.

\footnotetext{
Acknowledgements. The authors would like to thank W.K. Baker and K.P. Van de Woestijne for their helpful comments on an earlier draft of the paper.
}

\section{References}

1. Leventhal H. Symptom reporting: a focus on process. In: McHugh S, Vallis T, eds. Illness Behavior: a Multidisciplinary Model. New York, Plenum, 1986; pp. 219-237.

2. Peiffer C, Marsac J, Lockhart A. Chronobiological study of the relationship between dyspnea and airway obstruction in symptomatic asthmatic subjects. Clin Sci 1989; 77: 237-244.

3. Rubinfeld AR, Pain MC. Perception of asthma. Lancet 1976; 1: 882-884.

4. Nguyen B-P, Wilson SR, German DF. Patients' perceptions compared with objective ratings of asthma severity. Ann Allergy Asthma Immunol 1996; 77: 209-215.

5. Janson C, Björnsson E, Hetta J, Boman G. Anxiety and depression in relation to respiratory symptoms and asthma. Am J Respir Crit Care Med 1994; 149: 930-934.

6. Priel B, Heimer D, Rabinowitz B, Hendler N. Perceptions of asthma severity: the role of negative affectivity. $J A s$ thma 1994; 31: 479-484.

7. Kinsman RA, Dahlem NW, Spector S, Staudenmayer H. Observations on subjective symptomatology, coping behavior and medical decisions in asthma. Psychosom Med 1977; 39: 102-119.

8. Staudenmayer H, Kinsman RA, Dirks JF, Spector SL, Wangaard C. Medical outcome in asthmatic patients: effects of airways hyperreactivity and symptom-focused anxiety. Psychosom Med 1979; 41: 109-118.

9. Costa PT, McCrae RR. Neuroticism, somatic complaints, and disease: is the bark worse than the bite? J Pers 1987; 55: 299-316.

10. American Thoracic Society. Standards for the diagnosis and care of patients with chronic obstructive pulmonary disease (COPD) and asthma. Am Rev Respir Dis 1987; 136: 225-244.

11. Kinsman RA, Luparello T, O'Banion K, Spector S. Multidimensional analysis of the subjective symptomatology of asthma. Psychosom Med 1973; 35: 250-267.

12. Brooks CM, Richards JM, Bailey WC, Martin B, Windsor RA, Soong S-J. Subjective symptomatology of asthma in an outpatient population. Psychosom Med 1989; 51: 102108. 
13. Tellegen A, Lykken DT, Bouchard TJ, Wilcox KJ, Segal NL, Rich S. Personality similarity in twins reared apart and together. J Pers Soc Psychol 1988; 54: 10311039.

14. Juniper EF, Guyatt GH, Epstein RS, Ferrie PJ, Jaeschke R, Hiller TK. Evaluation of impairment of health-related quality of life in asthma: development of a questionnaire for use in clinical trials. Thorax 1992; 47: 76-83.

15. Dupont LJ, Rochette F, Demedts MG, Verleden GM. Exhaled nitric oxide correlates with airway hyperresponsiveness in steroid-naive patients with mild asthma. Am J Respir Crit Care Med 1998; 157: 894-898.

16. Siegel S, Castellan NJ. Nonparametric Statistics for the Behavioral Sciences, 2nd Edn. New York, McGraw-Hill, 1988.

17. Magnusson D. Personality development from an interactional perspective. In: Pervin LA, ed. Handbook of Personality. Theory and Research. New York, Guilford, 1990; pp. 193-222.

18. Cassileth BR, Lusk EJ, Strouse TB, et al. Psychosocial status in chronic illness: a comparative analysis of six diagnostic groups. $N$ EngI J Med 1984; 311: 506-511.

19. Herbert TB, Cohen S. Depression and immunity: a metaanalytic review. Psychol Bull 1993; 113: 472-486.

20. Vogele C, Steptoe A. Physiological and subjective stress responses in surgical patients. J Psychosom Res 1986; 30: 205-215.

21. Waltz M, Badura B, Pfaff H, Scott T. Marriage and the psychological consequences of a heart attack: a longitudinal study of adaptation to chronic illness after 3 years. Soc Sci Med 1988; 27: 149-158.

22. Watson D, Pennebaker J. Health complaints, stress, and distress: exploring the central role of negative affectivity. Psychol Rev 1989; 96: 234-254.

23. Harver A, Mahler DA. Dyspnea: sensation, symptom and illness. In: Mahler DA, ed. Dyspnea. Lung Biology in Health and Disease. Vol. 111. New York, Marcel Dekker, 1998; pp. 1-34.
24. Pennebaker JW, Epstein D. Implicit psychophysiology: effects of common beliefs and idiosyncratic physiological responses on symptom reporting. J Pers 1983; 51: 468496.

25. Nouwen A, Freeston M, Cournoyer I, Deschesnes F, Boulet L-P. Perceived symptoms during induced bronchospasm: the role of temporal adaptation and anxiety. Behav Res Ther 1994; 32: 623-628.

26. Dales RE, Kerr PE, Schweitzer I, Reesor K, Gougeon L, Dickinson G. Asthma management preceding an emergency department visit. Arch Intern Med 1992; 152: 2041-2044.

27. Dales RE, Schweitzer I, Kerr P, Gougeon L, Rivington R, Draper J. Risk factors for recurrent emergency department visits for asthma. Thorax 1995; 50: 520-552.

28. Levine JB, Covino NA, Slack WV, et al. Psychological predictors of subsequent medical care among patients hospitalized with cardiac disease. J Cardiopulm Rehabil 1996; 16: 109-116.

29. Harrison BDW. Psychosocial aspects of asthma in adults. Thorax 1998; 53: 519-525.

30. Kaptein AA. Psychological correlates of length of hospitalization and rehospitalization in patients with acute, severe asthma. Soc Sci Med 1982; 16: 725-729.

31. Staudenmayer H, Kinsman R, Jones N. Attitudes toward respiratory illness and hospitalization in asthma. Relationships with personality, symptomatology, and treatment response. J Nerv Mental Dis 1978; 166: 624-634.

32. Hudgel DW, Cooperson DM, Kinsman RA. Recognition of added resistive loads in asthma: the importance of behavioural styles. Am Rev Resir Dis 1982; 126: 121125.

33. Griffith SA. Review of the factors associated with patient compliance and the taking of prescribed medicines. $\mathrm{Br} J$ Gen Pract 1990; 40: 114-116.

34. Suissa S, Blais L, Ernst P. Patterns of increasing $\beta$-agonist use and the risk of fatal or near-fatal asthma. Eur Respir $J$ 1994; 7: 1602-1609. 